NISSUNA UMANA INVESTIGAZIONE SI PUO DIMANDARE VERA SCIENZIA S'ESSA NON PASSA PER LE MATEMATICHE DIMOSTRAZIONI LEONARDO DA VINCI

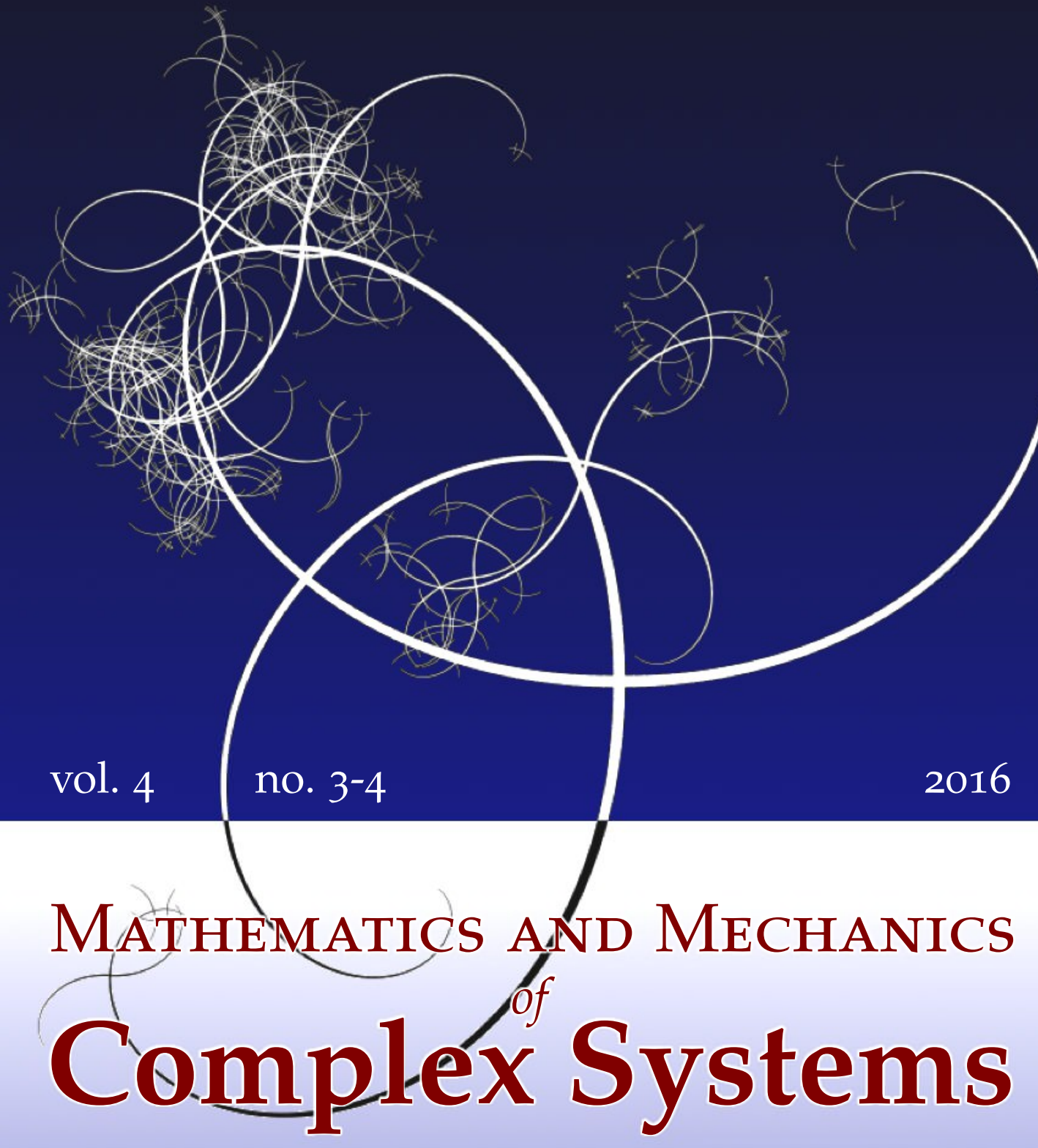

Claudio D’ Amato

AN ATTEMPT TO LET THE "TWO CULTURES" MEET: RELATIONSHIP BETWEEN SCIENCE AND ARCHITECTURE IN THE DESIGN OF GREEK TEMPLES. 


\title{
AN ATTEMPT TO LET THE “TWO CULTURES" MEET: RELATIONSHIP BETWEEN SCIENCE AND ARCHITECTURE IN THE DESIGN OF GREEK TEMPLES.
}

\author{
Claudio D’ Amato
}

\begin{abstract}
Editor's note: This unusual paper appears by invitation as an illustration of Lucio Russo's far-reaching influence. The author writes:

The present contribution is aimed at stimulating some reflections on the fracture existing (and enlarging) between what were famously called "the two cultures" by C. P. Snow in his influential book (Snow, C. P., The two cultures and the scientific revolution: The Rede Lecture. Cambridge Univ. P., 1959). The focus is on the architecture of Greek temples of Classical and Hellenistic age. At the same time, some possibility to fill the gap is described, based on my experience and my scientific interaction with Lucio Russo, to whom this editorial is dedicated.
\end{abstract}

\section{Introduction}

One of the theoretical issues which my cultural action in the Architecture School of Bari has been focused on, was the definition of a curriculum able to realize a conceptual unity of teachings of different nature (technical-scientific and historicalartistic) that contribute to train students. An action aimed at countering the globalization and the specialization of knowledge. In this strategy a major role was assigned, starting from the very first year of the course, to teaching classical architecture, in particular Greek, from which all of the theoretical principles and language of Western architecture until the nineteenth century derived. My relationship with Lucio Russo has to be considered within this cultural action: I owe to him a significant step in my teaching and research activities, about which I will speak in these pages.

I met Lucio Russo for the first time in January 2000, after reading his pamphlet Segmenti e Bastoncini, in which I immediately found a convergence of ideas on the importance of "classical" education in Higher School and on the criticism to the deconceptualization promoted by the reform of the (then) Minister Luigi Berlinguer. It was for me a very important meeting. He spoke me about the journal Punti 
critici (which he founded), and about the cultural action in which he was engaged at that time with many lectures in high schools. We also talked about La rivoluzione dimenticata, which I did not know, and that a few months later he came to present in Bari ${ }^{1}$.

In the following part of this editorial I will show some examples of the research approach I was used to before meeting Lucio Russo and later I will show how the scientific interaction with him changed this approach and the related results.

\section{My way of working before meeting Lucio Russo Case study 1: the replica of the capital 9A of the temple of Apollo Epicurius at Bassae ${ }^{2}$}

In 2000, from April to September, I was busy with my research group ${ }^{3}$ in the realization of the replica of the capital 9A of the temple of Apollo Epicurius (rescuer) in Bassae (Messenia). An experiment with which I was searching for a satisfactory transition from traditional techniques of cutting stones to those using numerical control machines. The goal was to improve the performance of architecture with load-bearing masonry systems (in terms of energy performance, cost, etc.) in comparison with that of reinforced concrete frame.

\footnotetext{
${ }^{1}$ May 22, 2000, Politecnico di Bari, Aula Magna "Attilio Alto".

$\mathbf{2}^{2}$ Tradition attributes its design to Ictinus (for a non-specialist approach to the problem, see the popular book by Rhys Carpenter, The Architects of the Parthenon, Penguin Books, 1970). The temple was dedicated to Apollo, who had come to the rescue (Epicurius $=$ rescuer) of the village of Bassae in Messenia victim of an epidemic. The temple constituted a prototype that spread in the following century beyond the geographical limits of the Peloponnesus, extending up to the boundaries of the Greek world. As concerns the exceptional nature of this temple W. B. Dinsmoor writes: "I believe we can say that within the perimeter of the peristyle may be found more fascinating problems than in any other building in the world of ancient Greece" (W. B. Dinsmoor, The temple of Apollo at Bassae, Metropolitan Museum Studies IV, New York, 1932-33). The temple is peripteral-hexastyle ( $6 \times 15$ columns) distinguished by the contemporary presence of the Doric order on the outside, in the peristyle, the pronaos and the opisthodome; and Ionic and Corinthian orders on the inside. Ionic are the columns standing against the spurs, which articulate the interior space of the cell and the frieze at the top, while the column placed on the axis of the cell is instead Corinthian.

${ }^{3}$ The experimental nature of the research project allowed us to:

- select as material Carrara marble, suitable for its degree of hardness to the technical characteristics of the set of tools (milling cutter and tips) available at the time of realization;

- produce a half capital, in consideration of its weight (approx. $1500 \mathrm{~kg}$ for a mean size of approx. $100 \times 60 \times 120)$.

The time required for study (defining the laws of composition and examination) and designing the three-dimensional model was approximately 30 days (April 2000); the time required for realization, about 5 days (September 2000). A large and detailed account of this experience is in C. D'Amato (2003). The formal unity of the Greek Temple. The realization of the 9A capital replica of Apollo epicurius' Temple at Bassai. In: First International Congress on Construction History, Madrid, 2024 January 2003, vol. I / 84-9728-071-7, p. 683-691, ISBN: 84-9728-070-9.
} 
We chose as a case study the Doric capital because in its seeming simplicity it is one of the most difficult and complex model, for its capacity to clearly demonstrate the thesis, since the apparent simplicity of its form, tolerates no imperfection in design or execution. And among the many possible, we choose that of the temple of Apollo Epicurius for its very urgent problems of restauration.

Replace it with a replica? We accepted the challenge, because we felt it was possible to accomplish the goal with the help of new technologies. But the real challenge were the conceptual problems beyond the specific case of the restoration until to the core of contemporary architectural design with its new modes of design and production.

In September, we presented the replica of the capital 9A at MarmoMacc of Verona ${ }^{4}$. We wanted to demonstrate the possibility of "replicating" (not copying) architectural elements irreparably damaged, of which it was perfectly known the shape and the geometric model.

We were convinced that it was possible to go back to the original design model, starting from the conceptual horizon and from the production way of classical Greece, that is from the design geometry and from their concrete "constructability"5.

The Greek Temple could be easily considered as a paradigm in this sense: here stone, used as unique material for the definition of the aesthetic character, expresses directly the structural and decorative geometrical texture, and also defines the formal unity of the architectural system as a whole. Moreover it is characterized by an exact design and perfection in execution, aspects that make it exemplary.

As I said, the damaged capital 9/A of Apollo Epicurius' Temple at Bassae, has been chosen for the elaboration of cad/cam processing software, and associated $3 \mathrm{D}$ virtual simulations for its realization with a $\mathrm{CNC}$ machining center.

This is a chance only if we know all the original project, not just its individual components; and also if we have the technology to run a perfect workmanship. Only if these conditions exist, we can speak of "replicas."

${ }^{4} 35$ th MarmoMacc, International Exhibition of Marble, Stone and Technology, Veronafiere, Saturday, September 30, 2000. Panel discussion: Stone-cutter of the twenty-first century. The replica of the capital 9A of the temple of Apollo at Bassae. Participants: C. D'Amato, S. Alevridis (Ephoria Z, Olympia), B. Cache (ETSAB, Barcelona), P. Marconi (Università Roma Tre), G. Margheriti (CMS), G. Rocco (Università di Chieti), J. Tzedakis (Ephoria Z, Olympia). This experience was the junction of all the research and practice of construction previously initiated by me in the School of Architecture of Bari (that can be defined "traditional") with the "stereotomic" one, favored by the use of numerical control machines and 3D modeling software.

${ }^{5}$ The geometric knowledge of the classical age was at the basis of Euclid's Elements. From it also were derived the instruments and methods used in the building site, such as e.g. the jigs and the rotation process. 


\section{Case study 2: the modelling of the capital 9A: structural geometries and computerized modelling techniques}

The "electronic" modelling of the capital 9A and of the eighth drum of its column, was conducted by processing the data derived from traditional survey (manual) on a scale of $1: 1$.

Capital 9A consists of a square-based parallelepiped abacus, an echinus whose contour is defined by a polycentric or spline curve, by a collarino and by the end of the fluting which is joined to the collarino through a complex surface.

The eighth drum 9A consists of a truncated cone with fluting and engraved end (hypotrachelion).

The identification of the different parts of the capital was done through computerized polygonal CAD modelling by "surfaces" and not by the parametrizing of "primitives" or "extrusion" of polygons, for the purpose of facilitating manipulation of the 3D object.

The abacus, a square-based parallelepiped volume, was obtained by the mutual and orthogonal composition of flat surfaces ("2D faces").

The echinus and the collarino, a single volume of rotation, are the result of a surface of revolution, obtained by rotating the profile of these elements for $360^{\circ}$ around an axis of radial symmetry.

The collarino, serving as union between the end of the fluting and the echinus, mathematically defined as quadric surface, was obtained through a "polar series" of a bilinear curved surface consisting of 20 elements through an angle of $360^{\circ}$. This surface was modelled in two successive stages: the first by interpolating a "Coon surface" for four spatial curves: the first of these is the portion of convex circumference termination of the annuli, contained in the horizontal plane included in an angle of $9^{\circ}$ (half of $360^{\circ} / 20$ ); the second is the profile of the fluting, contained in the vertical plane passing through the axis of radial symmetry; the third is the section measured at the centreline of the fluting, contained in the vertical plane passing through the axis of radial symmetry; the fourth is the portion of concave circumference at the base of the fluting contained in the horizontal plane. The surface determined in this way represents half of the global surface, which is completed, in the second stage, by "mirroring" the surface found according to the axis passing through the centre point of the fluting, perpendicular to the axis of radial symmetry.

The drum consists of a surface passing through three sections contained in horizontal and parallel planes, measured at different heights. The hypotrachelion has been obtained by generating a surface having as generatrix the raised profile (sawtooth section) contained in the vertical plane passing through the axis of radial symmetry, and as directrix the section of the drum, contained in the horizontal plane, at that height with the fluting. 


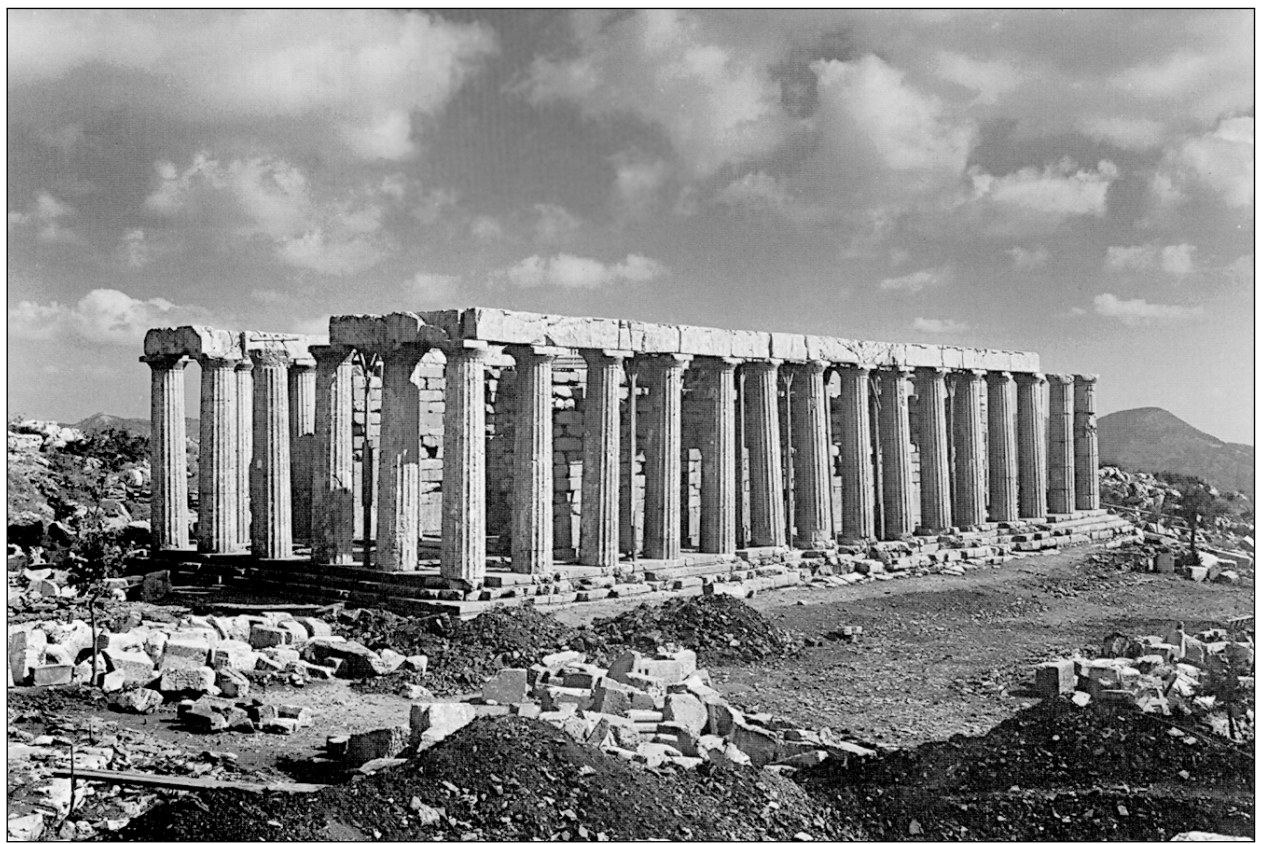

Figure 1. View of the temple of Apollo at Bassae from the northwest, before restoration work (Archive of the Ephoria Z, Olympia).

In October 2000 I gave start to a final synthesis course, whose topic was $D e$ signing and building with dry stone ${ }^{6}$ : the case study was the temple of Apollo at Bassae, and its theme of design was the remaking of its roof, in accordance with the procedures of anastylosis and integration with replicas of the missing pieces (whose geometric shape was known) or heavily damaged. On that occasion the idea of a seminar with Lucio Russo on design issues of the Greek temples of the classical age and the Hellenistic period was born.

\section{How my research approach changed after meeting Lucio Russo: the relationship between science and architecture in the design of Greek temples of the classical age and the Hellenistic period}

On 12 March 2001, Lucio Russo gave a seminar concerning the relationship between

\footnotetext{
${ }^{6}$ Tutors: Claudio D’Amato (Architectural design), Angelo Ambrosi (Architectural Drawing), Mauro Mezzina (Structure and construction); Students: M. Alicino, F. Aulicino, C. Carone, F. Cavone, V. Chieti, G. Dell'Aquila, S. Dentico, L. Donatelli, A. Paresce with the assistance of the PhD students Giuseppe Fallacara and Annalisa Di Roma. A campaign of surveys was carried out on April 9-12, 2001 in agreement with Ephoria Z of Olympia and in collaboration with the architect Sofoklis Alevridis of the Temple Commission.
} 
science and architecture in the design of Greek temples ${ }^{7}$. It was mainly focused on the "rules of correspondence" between the architectural project and its transfer, first "on paper" and then in its construction. So, a seminar that explored the Euclidean geometry as a tool which admits only geometric entities constructible with ruler and compass, on the basis of postulates.

Below there is a synthesis of some excerpts from the seminar of Lucio Russo.

The theorems: deductive method and theoretical entities of thinking. Let us focus on some methodological characteristics of the Hellenistic scientific theories, in the belief that some of these features are still valid in contemporary culture. Hellenistic science is an absolute novelty in the history of mankind, but if you take the books of history of science this novelty does not always emerge.

The scientific method has its roots in the culture of classical period, but emerges substantially in the 4th century B.C., and is characterized by two elements which are the deductive method and the existence of a purely theoretical level of thinking.

A typical case is that of the rational geometry of Euclid's Elements, where there are theoretical entities (triangles, circles, etc. in which no one stumbles walking in the street), and where the propositions can be proved with theorems, i.e. by means of arguments that logically link the statements to previously accepted ones, starting from the well-known five postulates. It is very interesting to think to the origin of the deductive method, which is an absolute novelty compared to earlier civilizations. In Greek civilization, the deductive method was prepared by other events that have to do with logic, in particular the analysis of the syllogism in Aristotle.

Deductive method and rhetoric. The aspect that should be emphasized is that there is a direct relationship between the demonstrative method and rhetoric. It is very interesting to read Aristotle's Rhetoric, in which it is clear that rhetorics gave rise to logic and not the converse. The syllogism, in particular, is identified as the only reasoning which resists to any confutation attempt. This was indeed an essential step in the development of logic.

Theoretical entities. There is a close relationship between the two components of Hellenistic science that are the logical reasoning within the theoretical model, i.e. the systematic use of the demonstrative method, and the theoretical nature of the entities. How were the theoretical entities thought? It is important to reflect on the fact that the Greeks did not have available a special language for the construction of a scientific theory, like the Greek language will be for the other civilizations. The later peoples have built the entire scientific terminology taking heavily from Greek

\footnotetext{
${ }^{7}$ Politecnico di Bari, AA 2000-2001 (XI), School of Architecture, via E. Orabona 4, Monday, March 12, 2001.
} 

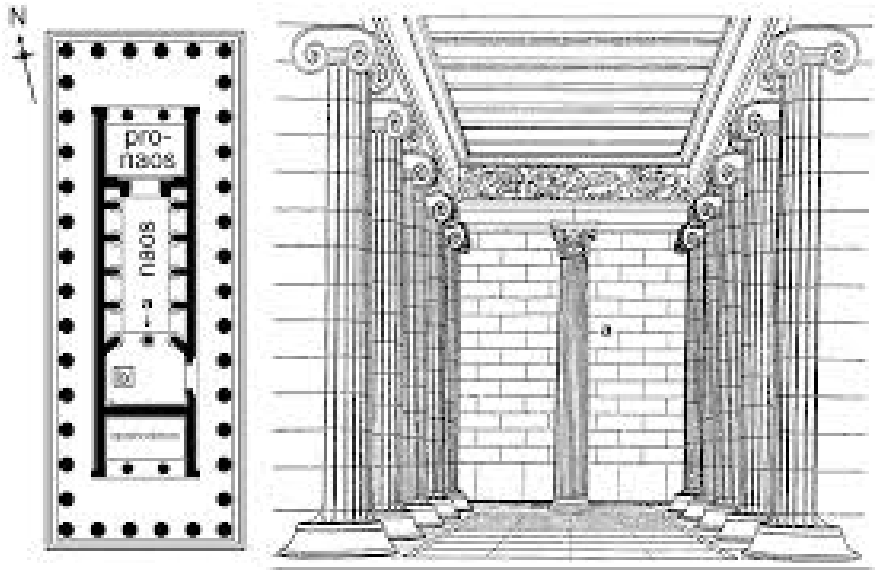

Figure 2. Floor plan and transverse section of the temple.

language, and this provided an additional tool to distinguish the technical term used from the conventional meaning that it used to have in the common language.

The Greeks of course could not do it: using the terms of their daily language, the process of abstraction had to be carried out in a somehow more conscious way. A simple example: when a student speaks, today, of a trapezium (or trapezoid, in North America), or when we talk of a circus trapeze, these words lack more mundane meanings. By contrast, a student in Euclid's time who spoke of a trapezium

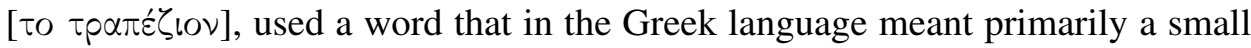
bench, and this required a more conscious level of abstraction.

Then how do you go from a real word to its abstraction? For example, with the word "straight line" it is obvious that we are referring to a geometric entity and not to a real object. So, in which way from a "straight line" that is a real object, which can be traced with a stylus, with a pen on a papyrus or on a sheet of paper, was born the straight line of geometry? A possible answer is that it arises precisely from the strictly deductive structure of the theory.

Deductive theory. A deductive theory consists of a set of propositions, all based on a few, basic assumptions that in the case of the Euclidean geometry are the "postulates". Considering admissible not all the statements but only those deductible rigorously with a deductive method from "postulates", narrows the semantic field of the term of ordinary language.

The "real" straight line can be green or red or can have any possible attribute; however, because none of the five postulates of Euclid speaks of colors, it is clear that no color will ever appear in any theorem. Nothing about colors is deducible from the postulates; colors are used in other contexts. Similarly there is no mention of thickness, and the thickness of a line will never appear in geometry. 


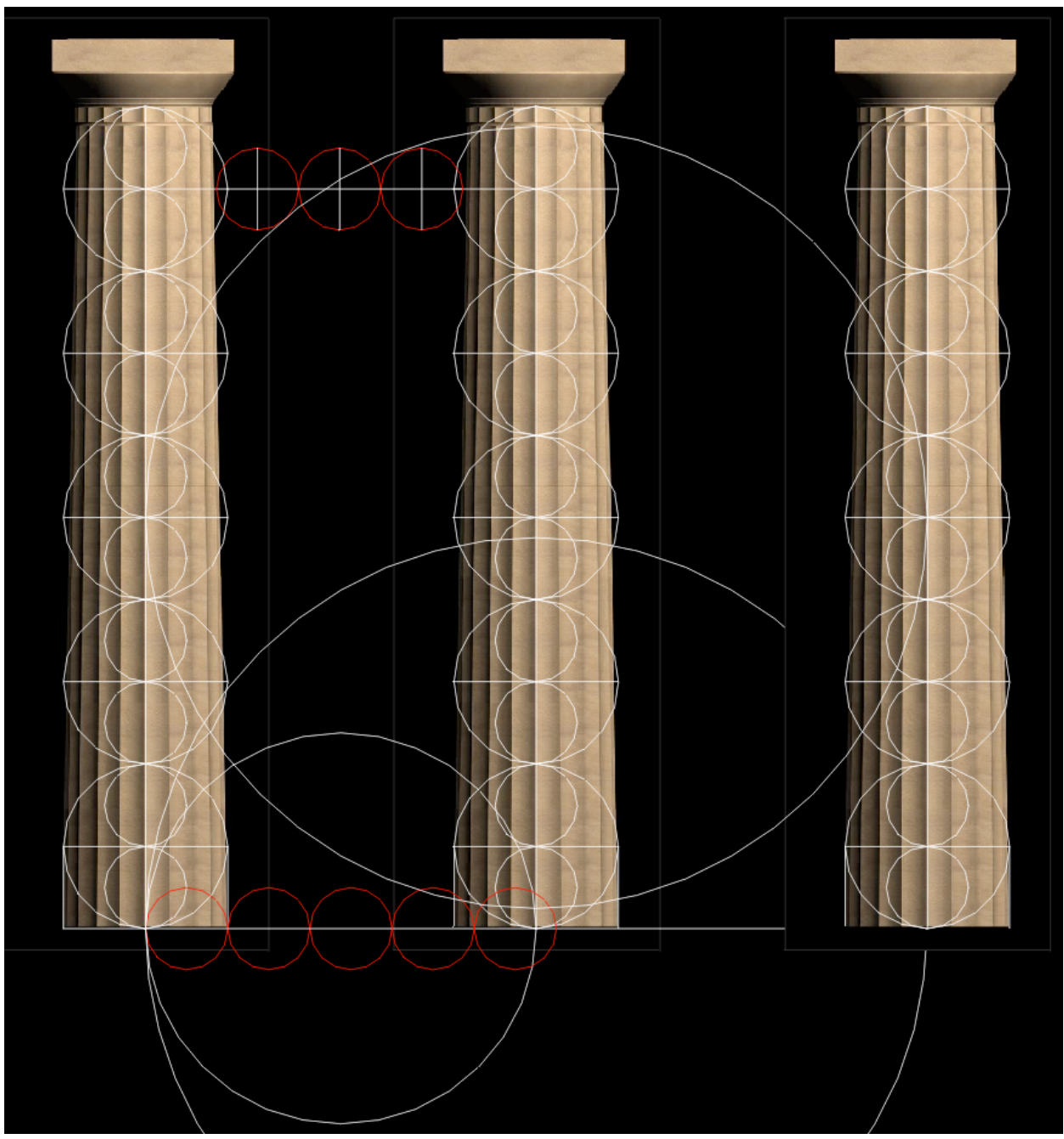

Figure 3. Proportional studies of the Doric order (external peristasis) of the temple of Apollo at Bassae (by G. Fallacara).

Theoretical concepts or postulates, and their constructability. Thus in this way a new concept arises that is the theoretical concept. But it is important to note that the postulates retain a role (that for instance the axioms have not in modern mathematics) in connecting the theory and the practical use of the language. The postulates have indeed a dual nature: from the point of view of the theory they are statements about theoretical entities, born thanks to their function; but in any case, they continue to be phrases with an "ordinary" meaning. For instance we are accustomed to think, thanks to the first postulate of Euclid, that the statement that a straight line passes through two points is seen an internal statement of the 

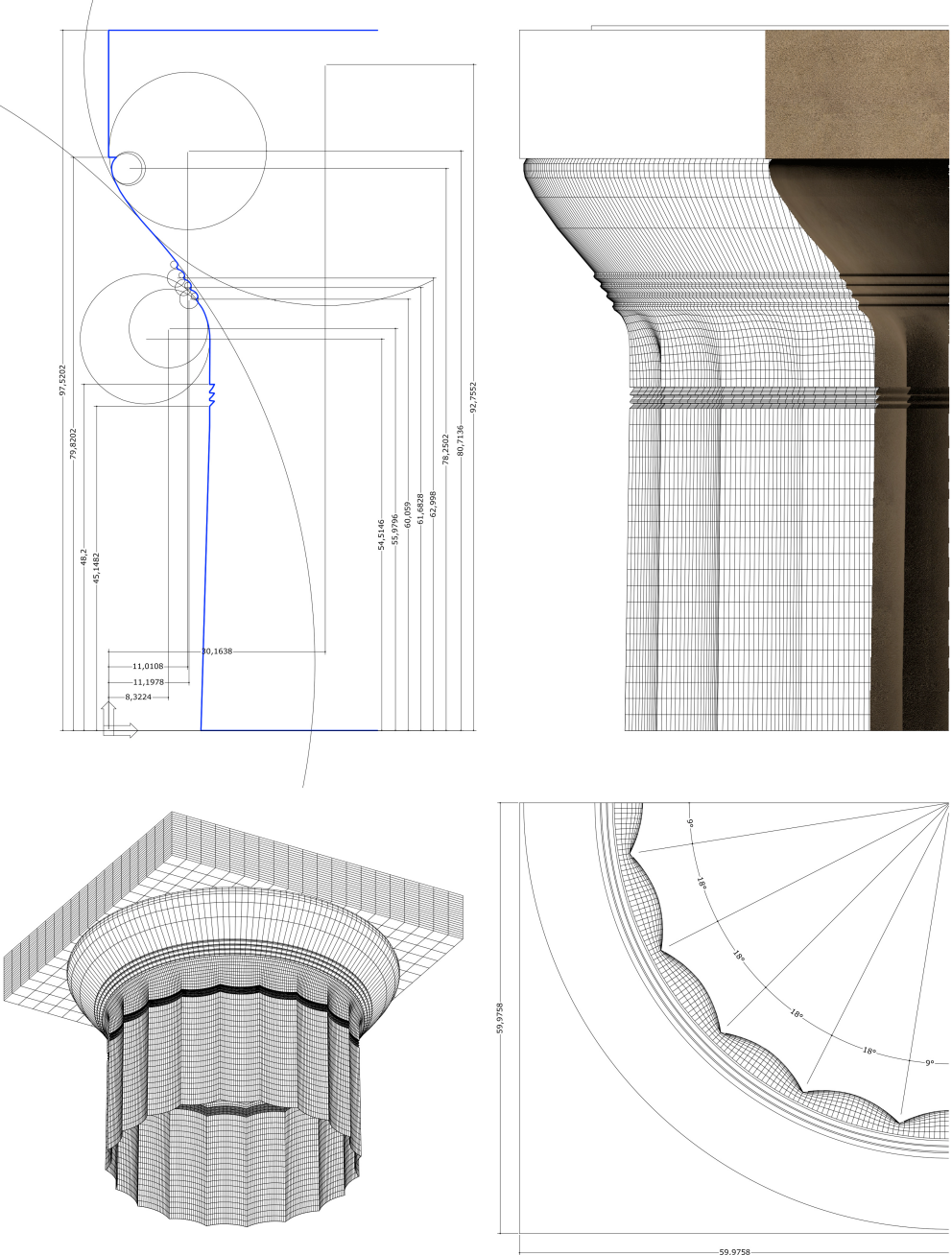

Figure 4. Constructive geometries of capital 9A (by G. Fallacara).

geometric theory which relates those abstract entities which are the points and the straight lines. If we make a literal translation of the first postulate of Euclid's Elements, namely that between two "signs" you can always draw a straight line, this statement has a meaning both from the point of view of the theory, but also refers to a real activity of drawing, and this allows a concrete application of the theory. When this connection is broken, you cannot understand anymore what is the relationship between theory and the real world.

The diffusion of the deductive method and the building of models. Eg. The hidraulycs, the astronomy. Another important aspect is the changes that these concepts experienced in the modern era, escaping to the original meanings. The 
scientific theories we are talking about are not mathematical theories in the current sense of the word mathematics; they have a much broader scope of application: for example, in his mechanics works, Archimedes uses exactly the same demonstration scheme we are talking about, but there he talks about machines and not of geometric drawings. And of course also the drawings are something real that is built like machines; think to the hydrostatic theories of Archimedes, or to the Treaty On Floating Bodies, which is concerned with a number of theorems on bodies floating in a fluid.

But the floating bodies of Archimedes are not the real and concrete bodies that float in the life of every day: with these they have the same ratio that the Euclidean straight line has with the straight line of the drawing. Indeed the floating bodies of Archimedes never undergo gusts of wind, the water does not swell, there is no surface tension, and so on. In other words, only those features of the floating bodies are maintained which are mentioned in the hydrostatic postulates. Everything else is automatically neglected. Ultimately, a model is built that considers only the consequences of a part of the characteristics chosen from the real world. The same thing happens in astronomy.

Hypotheses and postulates. A crucial point of these scientific theories is that they consist of theorems proved rigorously starting from some statements that are often defined "hypotheses" rather than postulates (the word often is regarded as synonymous of "postulates"). The term hypothesis derives from a Greek word that has a different meaning from the modern terminology, namely it is "the basis", what it is placed under, the foundation.

It is important to understand how you choose the hypotheses, how you choose the postulates. There are a number of statements which are very easily verifiable, but generally the postulates are neither simple nor verifiable. For instance, in the way in which Archimedes explains the heliocentric theory in the "Sand Reckoner", it is not at all easy to verify Aristarchus' "hypothesis" that the Earth moves and that the Sun is stationary, because all the experience through the millennia seems to say the opposite. So the postulates are not something whose truth is obvious. This also applies to the postulates of geometry, if only for their being so general: how do you verify that for any pair of signs you can always draw a straight line?

Nor we can assume the criterion of simplicity. The idea to start from the simple is a pre-Euclidean idea, coming from the Pythagorean School: if you want to build a geometry starting from the simplest entities, these should be the points. But it has never succeeded to build a geometry starting from the points, because aporias were always arising, because always there had been some problems. And then Euclid decided to start halfway, directly from the concepts of circles and straight lines, without starting from the concept of point, and this was a tremendous idea. 
The starting hypotheses are neither the easiest nor the most verifiable. But there is another fundamental criterion that must be satisfied, that is: from them it must be possible to deduce what is observed with a deductive method - what Plato called

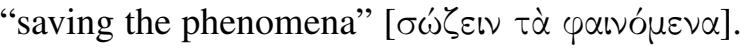

It is important to note that the phenomena are not intended here in the modern meaning of the word. There are two different starting points of the theory: one is the logical starting point that is the postulates of the theory; and then there is the starting point of the phenomena, that is all that you can immediately perceive with the senses.

In the case of astronomy, the starting point of the modern theory is the assumption that the sun is stationary and the earth moves, while the phenomenological starting point is the observation of planetary motions, in particular their retrograde movement. That is, we observe the motion of the planets, and notice that they move some times "forward" and sometimes "backward": here appearances are very complex and we try to save them, deducing the theory from simple hypotheses.

So, if we have some simple hypotheses from which it is possible to deduce what appears, then we have been able to build a valid scientific theory.

Hellenistic science and its applications. Hellenistic science was what it was precisely because, despite it changed the object of investigation compared to the classical philosophy, focusing in a sense "on the parts" rather than "on the entire", it kept the spirit of the old philosophy, the contemplative spirit that the Greeks called theoretical. Greek science was animated by the theoretical and contemplative force, which urges us to consider visible things as chinks through which you can access to the ones that are not directly accessible. This is an approach that the pragmatictechnological modern mentality seems to have lost, or at least marginalized. The explicit description of the process of abstraction that leads to the formation of geometric entities is typical of Greek culture. The idea of solving problems with theorems is a typical Greek cultural product, that no other civilization had conceived.

So, the superiority of the Greeks on other peoples on this particular point, is not purely quantitative but qualitative, because what they created, establishing philosophy, is a novelty in some absolute sense. Indeed, it was the philosophy, because of its rational categories, to make possible the birth of science and, in a sense, to generate it.

Constructible geometric entities. Let us go back to theorems. In order to create theorems you must first have developed the logic, as Greeks did analyzing the forms of reasoning used in speeches; and then you have to try to derive a large number of logical propositions from very few propositions, chosen as postulates. 

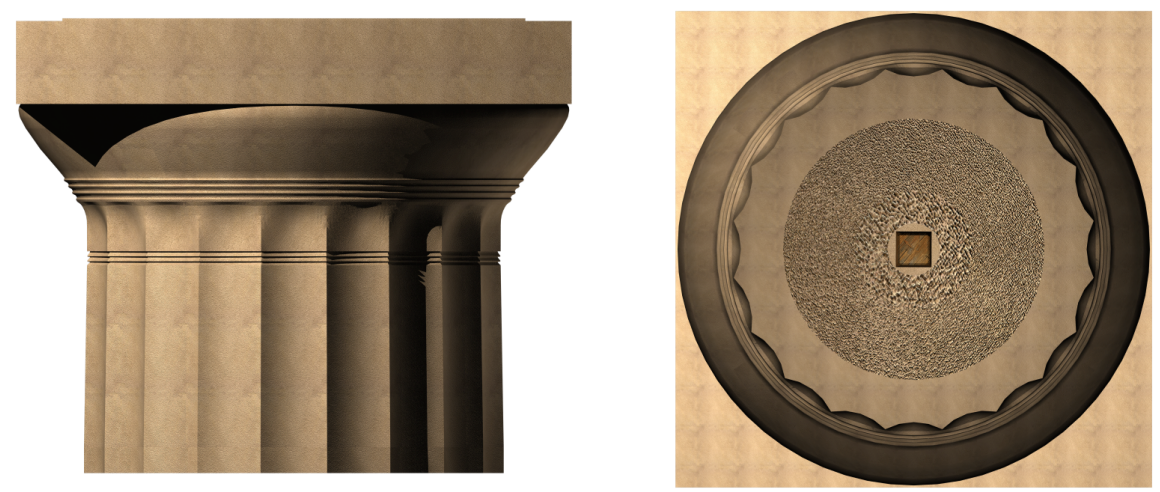

Figure 5. Left: virtual reconstruction of capital $9 \mathrm{~A}$ and its drum (by G. Fallacara). Right: virtual reconstruction of horizontal section of capital 9A with its empolion (from bottom).
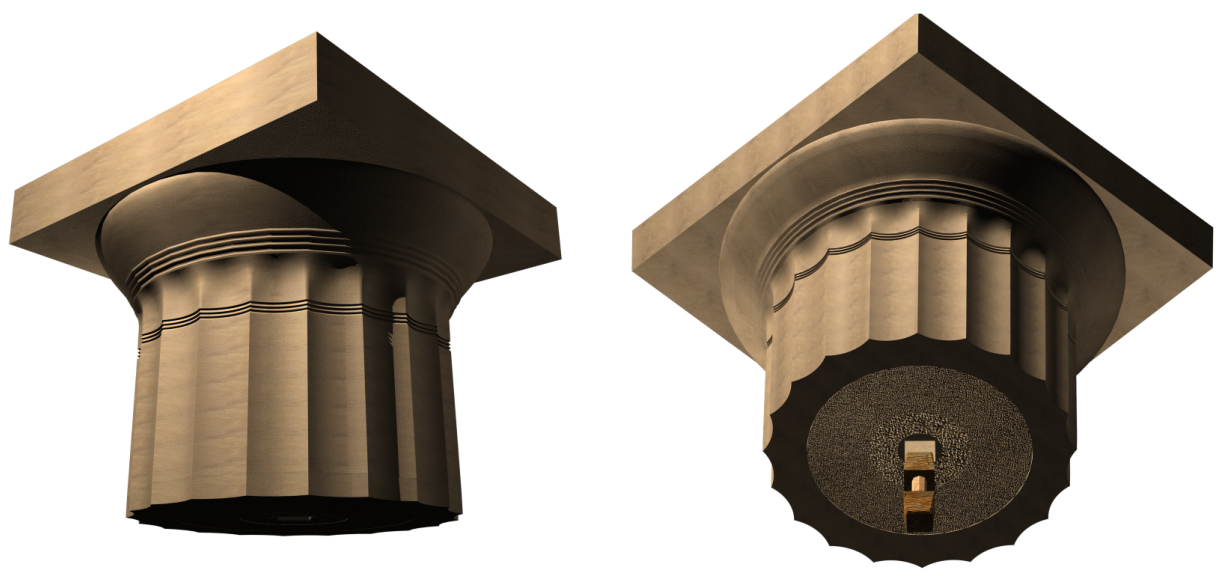

Figure 6. 3D view of capital 9A, from above and below.

It must then be determined which geometric entities are possible subject of mathematical proofs. The choice made by Euclid is to admit only constructible geometric entities on the basis of the postulates, that is, with a ruler and a compass.

\section{Conclusions: a research paradigm was changed due to the meeting of the "two cultures"}

As a conclusion, I want to come back to the impact of Russo's way of thinking on my work by briefly mentioning a few research products of the aforementioned lines of thought. In 2001-2003 the author supervised the PhD Thesis: Serial production 


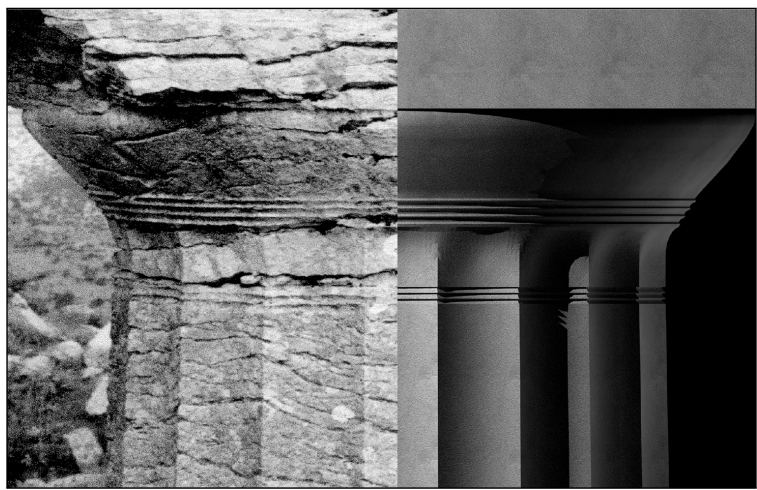

Figure 7. Comparison between the real capital and its virtual reconstruction.

in the architectonic ornamentations: from Hellenistic age to prototyping processes with CAD-CAM techniques ${ }^{8}$. This research object was a result of the investigation on the diversity between the mode of production of the Greek classic architecture and the Hellenistic one, developed also through the comments of Lucio Russo to our observations on the Hellenistic building site, to its methods and to the techniques of cutting the stone. A year later the seminar on the temple of Apollo at Bassae, it was promoted a symposium devoted to architecture in cut stone and to the stereotomy. ${ }^{9}$ The title was Architecture and stereotomy, tradition and innovation. ${ }^{10}$ This was an important moment of transition between the previous research

\footnotetext{
${ }^{8} \mathrm{PhD}$ Student: Annalisa Di Roma.

9"Stereotomy, from the Greek words $\sigma \tau \varepsilon \rho \varepsilon o=$ solid and $\tau o \mu \eta=$ cutting, is the science of cutting the solids (stone and wood) that through projective graphic techniques is able to determine the exact forms of the elements constituting the architectural system, and to realize them.

It combines the set of geometric codified procedures, consistent and repeatable, able to design and to represent whole buildings, or parts thereof, made of stone or wood. ... By extension of meaning, stereotomy stood to indicate during the 16th, 17th and 18th centuries the Art of Building, or Baukunst or Art de Batir." In C. D'Amato, Studiare l'architettura, Roma, Gangemi, 2014, p. 27.

${ }^{10}$ The initiative was taken by the Department of Civil Engineering and Architecture of Politecnico di Bari and the Department of Representation and Survey of the University of Rome "La Sapienza." The sessions were:

1) From survey to model (M. Docci, A. Ambrosi);

2) Mathematical model and numerical model (R. Migliari, Trevisan C.);

3) Idea, design, construction (C. D'Amato, S. Alevridis);

4) The replica of capital 9A of the temple of Apollo at Bassae (CMS);

5) Practical applications (G. Falcone, G. Valenti, V. Cascione, G Fallacara, A. Di Roma);

6) Theories, methods and instrumentation of contemporary stereotomy (L. Nisi, M. Curuni, M. Ciammaichella, E. Guglielmotti);

7) Theories, methods and tools of traditional stereotomy (E. Rabasa Diaz, M. Greco and M. Sganga, C. Bianchini, M. Fasolo, M. Alicino and V. Chieti, A. Di Roma, E. De Nichilo, G. Fallacara, G. Pinto, G. Radicchio, C. Zaccaria, P. Perfido).
} 
on architecture in cut stone, both with traditional methods and CNC machines, and the study of stereotomic architecture that would characterize my research in the following years.

Finally, I want to mention that the mature fruit of this season was the birth of Classic curriculum in the degree course in architecture of the School of architecture of Bari.

Since the academic year 2005-2006 the School of Architecture of Bari offers, together with a General curriculum, a Classical one. This is mostly inspired by the archeologic studies and by the Bauforschung, the consolidated tradition of studies in the Germanic world between 19th and 20th centuries about the knowledge of ancient architecture. Today this curriculum is not offered by other Schools of Architecture all over the world. In this School scientific knowledge, mathematical thought and physical theories are highlighted as fundamental ingredients for the basic education of young architects.

Received 7 Nov 2016. Revised 10 Oct 2017. Accepted 27 Oct 2017.

Claudio D'Amato: claudio.damatoguerrieri@poliba.it 
EDITORIAL BOARD

ANTONIO CARCATERRA

ERIC A. CARLEN

FRANCESCO DELL'ISOLA

RAFFAELE ESPOSITO

ALBERT FANNJIANG

Gilles A. FranCFORT

Pierangelo MARCATI

JEAN-JACQUES MARIGO

PETER A. MARKOWICH

MARTIN OSTOJA-STARZEWSKI

PIERRE SEPPECHER

DAVID J. STEIGMANN

PAUl STEINMANN

PierRe M. SuQueT

MANAGING EDITORS

MICOL AMAR

CORRADO LATTANZIO

ANGELA MADEO

MARTIN OSTOJA-STARZEWSKI

ADVISORY BOARD

ADNAN AKAY

Holm AltenBaCH

MICOL AMAR

HARM ASKES

TEODOR ATANACKOVIĆ

VICTOR BERDICHEVSKY

GUY BOUCHITTÉ

ANDREA BRAIDES

ROBERTO CAMASSA

MAURO CARFORE

ERIC DARVE

FELIX DARVE

ANNA DE MASI

GianPiEtro DEL Piero

EMMANUELE Di BENEDETTO

BERNOLD FIEDLER

IRENE M. GAMBA

DAVID Y. GAO

SERGEY GAVRILYUK

TIMOTHY J. HEALEY

DOMINIQUE JEULIN

ROGER E. KHAYAT

CORRADO LATTANZIO

ROBERT P. LIPTON

ANGELO LUONGO

ANGELA MADEO

JUAN J. MANFREDI

CARLO MARCHIORO

GÉRARD A. MAUGIN

ROBERTO NATALINI PATRIZIO NEFF

ANDREY PIATNITSKI

ERRICO PRESUTTI

MARIO PULVIRENTI

LUCIO RUSSO

Miguel A. F. SANJUAN

PATRICK SElVADURAI

ALEXANDER P. SEYRANIAN

MIROSLAV ŠILHAVÝ

GUIDO SWEERS

ANTOINETTE TORDESILLAS

LEV TRUSKINOVSKY

JUAN J. L. VELÁZQUEZ VINCENZO VESPRI ANGELO VULPIANI msp.org/memocs

Università di Roma "La Sapienza", Italia

Rutgers University, USA

(CO-CHAIR) Università di Roma "La Sapienza", Italia

(TREASURER) Università dell'Aquila, Italia

University of California at Davis, USA

(CO-CHAIR) Université Paris-Nord, France

Università dell'Aquila, Italy

École Polytechnique, France

DAMTP Cambridge, UK, and University of Vienna, Austria

(CHAIR MANAGING EDITOR) Univ. of Illinois at Urbana-Champaign, USA

Université du Sud Toulon-Var, France

University of California at Berkeley, USA

Universität Erlangen-Nürnberg, Germany

LMA CNRS Marseille, France

Università di Roma "La Sapienza", Italia

Università dell'Aquila, Italy

Université de Lyon-INSA (Institut National des Sciences Appliquées), France

(CHAIR MANAGING EDITOR) Univ. of Illinois at Urbana-Champaign, USA

Carnegie Mellon University, USA, and Bilkent University, Turkey

Otto-von-Guericke-Universität Magdeburg, Germany

Università di Roma "La Sapienza", Italia

University of Sheffield, UK

University of Novi Sad, Serbia

Wayne State University, USA

Université du Sud Toulon-Var, France

Università di Roma Tor Vergata, Italia

University of North Carolina at Chapel Hill, USA

Università di Pavia, Italia

Stanford University, USA

Institut Polytechnique de Grenoble, France

Università dell'Aquila, Italia

Università di Ferrara and International Research Center MEMOCS, Italia

Vanderbilt University, USA

Freie Universität Berlin, Germany

University of Texas at Austin, USA

Federation University and Australian National University, Australia

Université Aix-Marseille, France

Cornell University, USA

École des Mines, France

University of Western Ontario, Canada

Università dell' Aquila, Italy

Louisiana State University, USA

Università dell'Aquila, Italia

Université de Lyon-INSA (Institut National des Sciences Appliquées), France University of Pittsburgh, USA

Università di Roma "La Sapienza”, Italia

Université Paris VI, France

Istituto per le Applicazioni del Calcolo "M. Picone", Italy

Universität Duisburg-Essen, Germany

Narvik University College, Norway, Russia

Università di Roma Tor Vergata, Italy

Università di Roma "La Sapienza”, Italia

Università di Roma “Tor Vergata”, Italia

Universidad Rey Juan Carlos, Madrid, Spain

McGill University, Canada

Moscow State Lomonosov University, Russia

Academy of Sciences of the Czech Republic

Universität zu Köln, Germany

University of Melbourne, Australia

École Polytechnique, France

Bonn University, Germany

Università di Firenze, Italia

Università di Roma La Sapienza, Italia

MEMOCS (ISSN 2325-3444 electronic, 2326-7186 printed) is a journal of the International Research Center for the Mathematics and Mechanics of Complex Systems at the Università dell'Aquila, Italy.

Cover image: "Tangle” by $\odot$ John Horigan; produced using the Context Free program (contextfreeart.org).

PUBLISHED BY

7 mathematical sciences publishers

nonprofit scientific publishing

http://msp.org/

(C) 2016 Mathematical Sciences Publishers 
Special issue in honor of

Lucio Russo

Lucio Russo: A multifaceted life

Raffaele Esposito and Francesco dell'Isola

The work of Lucio Russo on percolation Geoffrey R. Grimmett

"Mathematics" and "physics" in the science of harmonics Stefano Isola

From quantum to classical world: emergence of trajectories in a quantum system Rodolfo Figari and Alessandro Teta

Propagation of chaos and effective equations in kinetic theory: a brief survey Mario Pulvirenti and Sergio Simonella

What decides the direction of a current? Christian Maes

A remark on eigenvalue perturbation theory at vanishing isolation distance Fiorella Barone and Sandro Graffi

Some results on the asymptotic behavior of finite connection probabilities in percolation Massimo Campanino and Michele Gianfelice

Correlation inequalities for the Potts model Geoffrey R. Grimmett

Quantum mechanics: some basic techniques for some basic models, I: The models Vincenzo Grecchi

Quantum mechanics: some basic techniques for some basic models, II: The techniques Vincenzo Grecchi

On stochastic distributions and currents

Vincenzo Capasso and Franco Flandoli

A note on Gibbs and Markov random fields with constraints and their moments Alberto Gandolfi and Pietro Lenarda

Quantum mechanics: light and shadows (ontological problems and epistemic solutions) Gianfausto Dell'Antonio

MEMOCS is a journal of the International Research Center for the Mathematics and Mechanics of Complex Systems at the Università dell' Aquila, Italy.

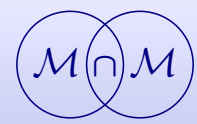

